\title{
Correction to: Toxicity of ayahuasca after 28 days daily exposure and effects on monoamines and brain-derived neurotrophic factor (BDNF) in brain of Wistar rats
}

\author{
Camila Schoueri Colaço ${ }^{1}$. Stefany Sousa Alves ${ }^{1}$ - Luciana Marangni Nolli ${ }^{1} \cdot$ Willie Oliveira Pinheiro ${ }^{2}$. \\ Danilo Gustavo Rodrigues de Oliveira ${ }^{3}$ - Beatriz Werneck Lopes Santos ${ }^{1}$ - Aline Pic Taylor ${ }^{2}$. Márcia Renata Mortari ${ }^{3}$. \\ Eloisa Dutra Caldas ${ }^{1}$
}

Published online: 1 October 2021

(c) Springer Science+Business Media, LLC, part of Springer Nature 2021

Correction: Metabolic Brain Disease, 35, 739-751 (2020)

https://doi.org/10.1007/s11011-020-00547-w

In the original article, Fig. 3 was erroneously duplicated, and the first copy was mis-labelled as Fig. 2. The correct Fig. 2 is shown below.

The original article can be found online at https://doi.org/10.1007/ s11011-020-00547-w.

Eloisa Dutra Caldas

eloisa@unb.br

1 Laboratory of Toxicology, Faculty of Health Sciences,

University of Brasilia, Brasilia, DF, Brazil

2 Laboratory of Embryology and Developmental Biology,

Department of Genetic and Morphology, Institute of Biology,

University of Brasilia, Brasilia, DF, Brazil

3 Laboratory of Neuropharmacology, Department

of Physiological Sciences, Institute of Biological Sciences,

University of Brasilia, Brasilia-DF, Brazil 

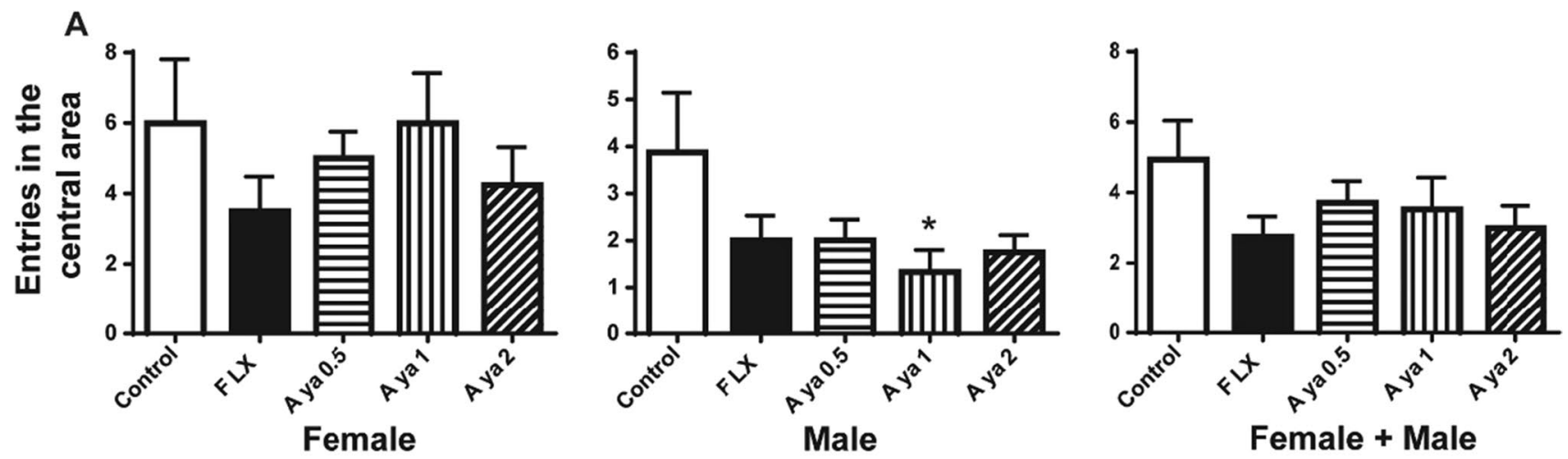

\section{B}

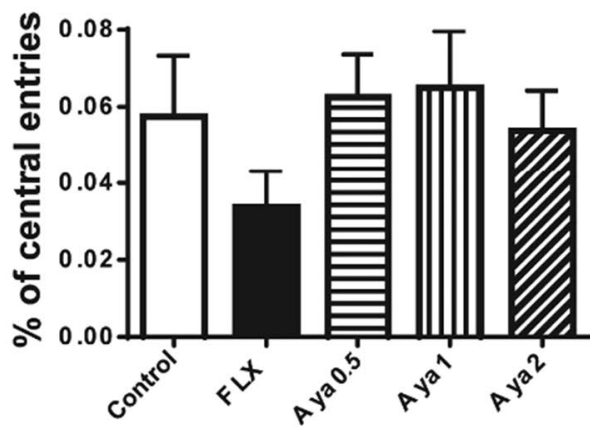

Female

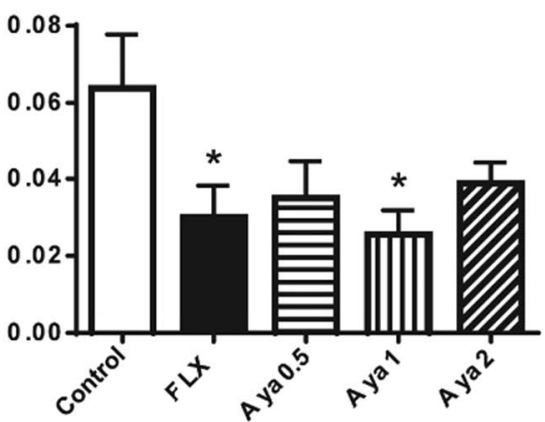

Male

Female + Male

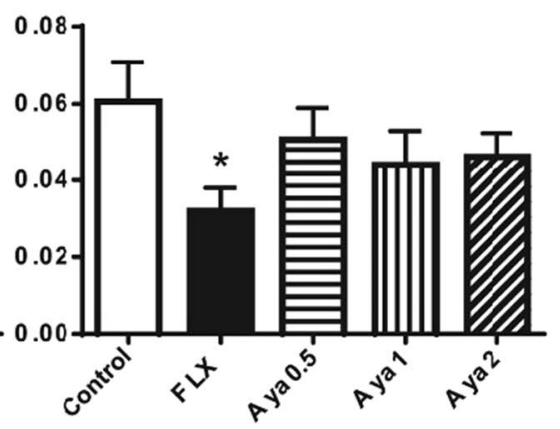

Female + Male

Fig. 2 A: Exploration of the central area of the open field (number of entries) and B: \% of central entries

Publisher's note Springer Nature remains neutral with regard to jurisdictional claims in published maps and institutional affiliations. 